VITAL

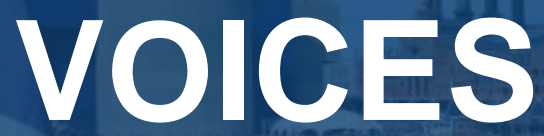

Issues That Impact Maryland Adults Age 45 and Older, November 2021

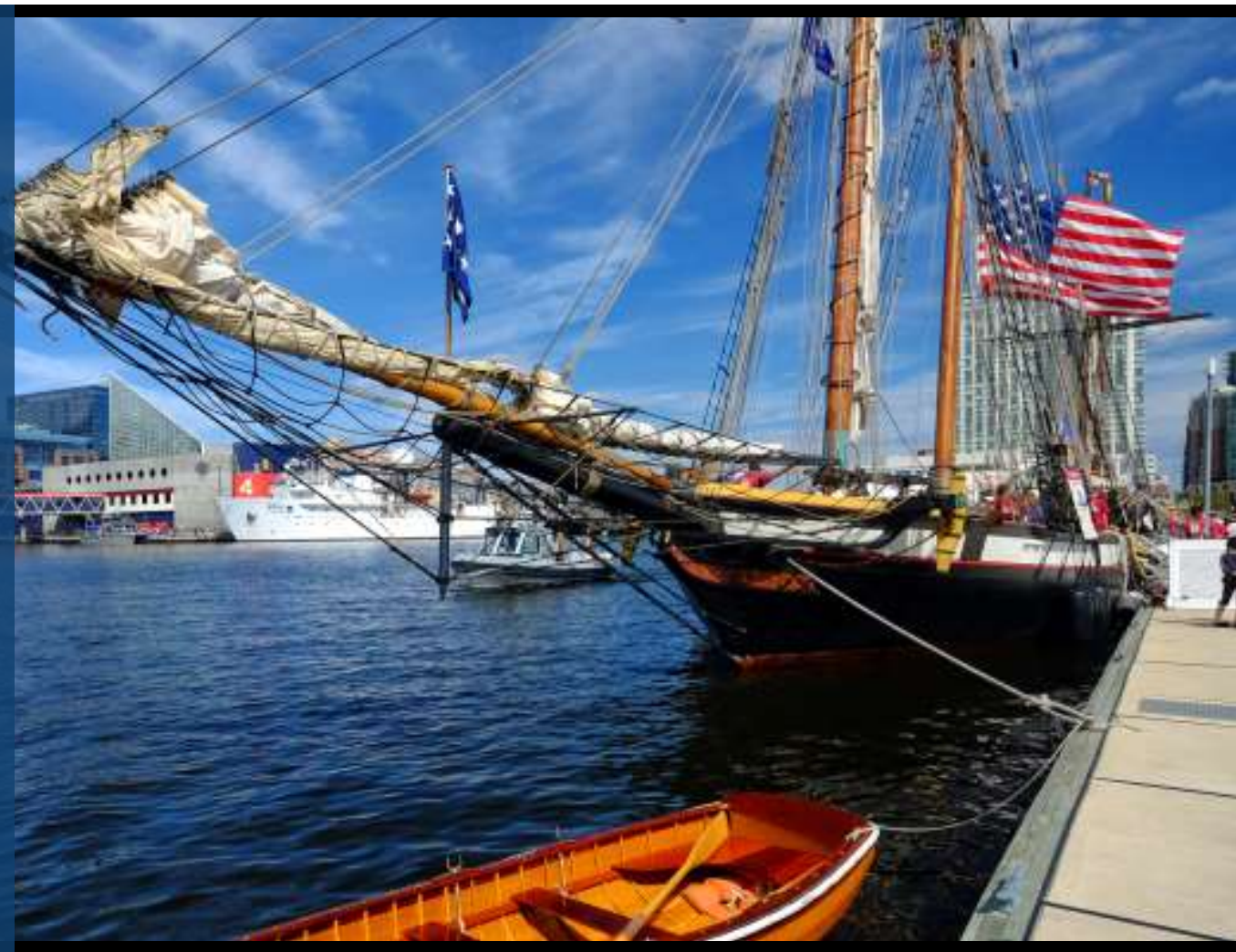

Issues of Importance to Maryland Adults Age 45+

\section{Health Care}

\section{Staying mentally sharp \\ Staying physically}

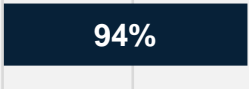
healthy

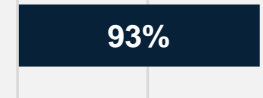

Adequate health insurance coverage

Medicare benefits available in the future

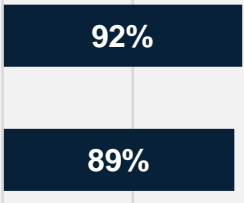

Paying for health care expenses

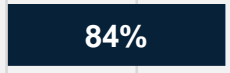

Paying for prescription drugs

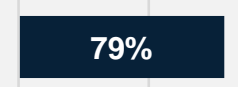

$0 \% \quad 50 \% \quad 100 \%$

\section{Economic/Financial}

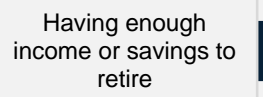

\section{$95 \%$}

Adequate Social Security benefits

\section{$89 \%$}

Protection against unfair financial practices

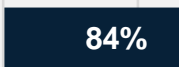

Protection against consumer fraud

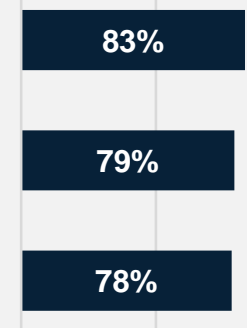

Having online security

$0 \%$

Being able to stop working for pay at the

age you want

\section{Independent Living/ Long-Term Care}
Getting the places you need to go independently

$86 \%$

Staying in your own home as you get older

$84 \%$

Caring for a loved one

$83 \%$

Having high quality long-term care

$80 \%$
"For the following list of issues, please indicate how important each is to you personally." $\%$ "extremely important" or "very important" 
Vital Voices: Issues That Impact Maryland Adults Age 45 and Older, November 2021

Interviews were conducted with 704 residents of Maryland by landline (50\%), cell phone (25\%), and online (25\%) between October 29, 2021 and November 10, 2021.

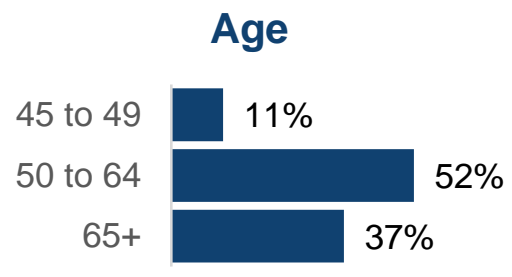

Employment

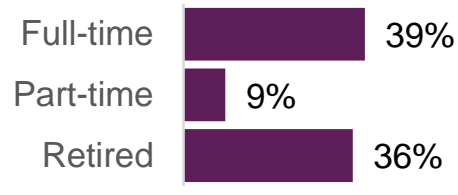

\section{Gender}

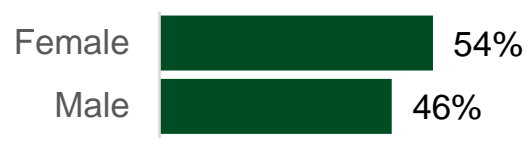

Race/Ethnicity

White/ Caucasian

Black/ African American

Asian

Other

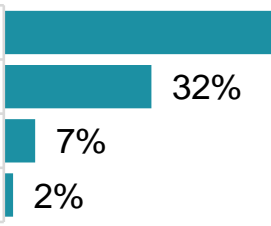

Political Views

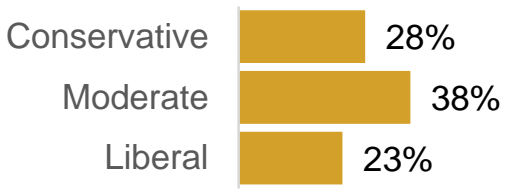

$59 \%$

\section{Education}

Some college or less

4-year college degree

Post-graduate study or degree

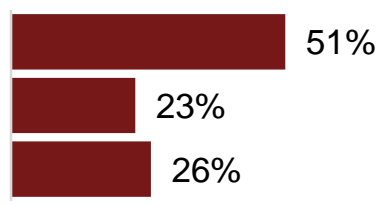

\section{Marital Status}

Married/ living with partner

Divorced/ separated

Widowed

Never married

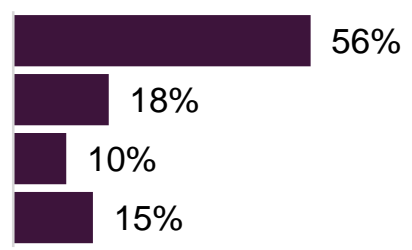

\section{Annual Household Income}

Less than $\$ 50,000$

$\$ 50,000$ to less than $\$ 100,000$

$\$ 100,000_{+}$

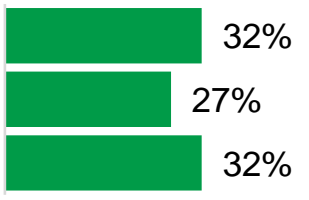

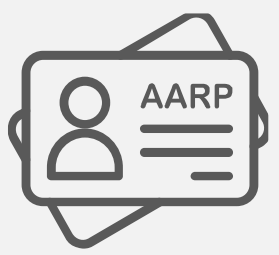

$41 \%$

AARP Member

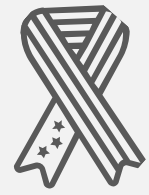

$16 \%$

Veteran 